\title{
SOIL MICROBIOME: DIVERSITY, ACTIVITY, FUNCTIONAL AND STRUCTURAL SUCCESSIONS
}

\author{
Lyudmyla Symochko ${ }^{1,2 *}$ \\ ${ }^{1 *}$ Uzhhorod National University, Voloshyna Str. 32, 88000, Uzhhorod, Ukraine; \\ ${ }^{2}$ Institute of Agroecology and Environmental Management NAAS, Metrologichna Str., 12, Kyiv, 03143, Ukraine; \\ "Corresponding Author Lyudmyla Symochko, email: 1yudmilassem@gmail.com;
}

Received January 2020; Accepted February 2020; Published March 2020;

DOI: https://doi.org/10.31407/ijees10.206

\begin{abstract}
The article presents original results of research. The aim of this study was long term investigation of soil microbiome in primeval forest ecosystems, namely the structure of microbial communities, the number of major ecological-functional groups, functional parameters such as: enzymatic activity of the soil by the level of catalase and invertase. To analyze impact of endogenous and exogenous factors on soil microbial community and succession processes. Estimate biodiversity of soil microbiome by Shannon index in different edaphotopes of primeval forest ecosystems. Microbiological studies of soil were carried out according to generally accepted methods in soil microbiology. Enzymatic activity of the soil: catalase - was determined by gasometric method and invertase - by colorimetric method. Statistical analyses were performed by using Statistica 10 software. Basic descriptive statistics was calculated, that is, the arithmetic mean and standard deviation. The influence of endogenous and exogenous factors in primeval forest ecosystems of Shyrokoluzhansky massif of the Carpathian Biosphere Reserve caused changes in microbial community. For ten years changed diversity and functional activity of soil microbiome. Based on long-term studies of changes in soil microbial communities of natural ecosystems, a succession concept of soil microbiome has been proposed.
\end{abstract}

Keywords: ecosystem, succession, soil, diversity, microbiome, enzyme activity. 